\title{
EL MAGISTERIO DE LOS SEGUNDOS SOFISTAS, SEGÚN FILÓSTRATO
}

PILAR GÓMEZ ${ }^{1}$

\begin{abstract}
RESUMEN: El objetivo de este trabajo es analizar, por una parte, cómo Filóstrato describe la relación maestro-discípulo entre los representantes de la Segunda Sofística mencionados en Vida de Sofistas, dado que es un elemento esencial en su caracterización como símbolo de prestigio e influencia y, sin duda, cohesiona el conjunto de los sofistas como grupo representante de una élite cultural. En segundo lugar, el trabajo intenta sistematizar cuál es el contenido de esas enseñanzas y en qué aspecto de la actividad de un sofista incide.
\end{abstract}

Palabras clave: Filóstrato - Segunda Sofística - retórica - educación.

ABSTRACT: The aim of this paper is to analyze, on the one hand, how Philostratus describes the teacher-disciple relationship between the representatives of the Second Sophistic mentioned in the Lives of Sophists, since this interrelation is an essential element to characterize them as symbolic figures of prestige and influence and, undoubtedly, it unites the set of the sophists as a representative group of a cultural elite-; and, secondly, to try to systematize what is the content of those teachings and what aspect of the sophistic activity affects.

Keywords: Philostratus - Second Sophistic - rhetoric - education.

\section{INTRODUCCIÓN: DOS SOFÍSTICAS}

En el s. III d. C. Filóstrato acuñó el término Segunda Sofística, diferenciando

\footnotetext{
${ }^{1}$ Universidad de Barcelona. E-mail: pgomez@ub.edu

Fecha de recepción: 19/10/2021; fecha de aceptación: 16/12/2021.

DOI: https://doi.org/10.46553/sty.30.30.2021.p155-181

Stylos. 2021; 30 (30); pp. 155-181; ISSN: 0327-8859; E-ISSN: 2683-7900
} 
el uso que los griegos hicieron de la retórica en el s. V a. C. y con posterioridad a ese momento. Sin embargo, Filóstrato no explica qué entiende por sofista, sino que su clasificación revela una voluntad de definir a los sofistas del Imperio por oposición a los sofistas de la Atenas clásica; y ese contraste es el que ha llevado, en general, a situar a los antiguos sofistas en relación con la filosofía y a vincular a los sofistas del Imperio con la retórica y la literatura. $^{2}$

En el mundo griego de época clásica la aparición de los sofistas coincide con la plena consolidación de la pólis como forma de organización humana y, en particular, con el afianzamiento de la estructura democrática de que se dotó la ciudad-estado por excelencia, Atenas. A diferencia de los filósofos que planteaban innumerables cuestiones y obtenían progresos mínimos en su investigación porque decían no conocer aún, los sofistas a los que Filóstrato llama antiguos, iniciaban sus discursos con expresiones como "Yo sé", "Conozco", "Nada es seguro para el hombre"; y tales fórmulas preliminares -según Filóstrato- denotaban en los discursos calidad, inteligencia y dominio de $s u$ verdad. ${ }^{3}$ Porque para los sofistas -tan demonizados por la historia de la filosofía, pero fundadores del pensamiento retórico mismo- no

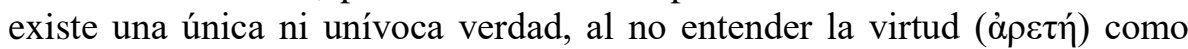
bondad, desde una perspectiva ética, sino como el conocimiento y la habilidad necesarios para tener éxito desde una perspectiva práctica. Por ello, su énfasis en la retórica se apoyaba en convencer a alguien de alguna de las cosas verosímiles que se pueden expresar con el lenguaje por mor de la magia de la palabra.

Así pues, a pesar de la taxonomía de Filóstrato, el manejo de la retórica no fue privativo de los sofistas de la segunda generación. En griego, el término retórica, como forma adjetiva, suele acompañar al substantivo $\tau \dot{\varepsilon} \chi v \eta$, e indica la cualidad de un arte, de una técnica; y si $\tau \dot{\varepsilon} \chi v \eta$ denota una habilidad para ejecutar y conseguir algo, la revolución sofística, en el s. V a. C., significó que esa habilidad en el ámbito de la pragmática del discurso podía ser aprendida y, por lo tanto, podía enseñarse, de manera que el uso de la pa-

${ }^{2}$ Sobre la construcción de la Segunda Sofística por parte de Filóstrato, véase CôTÉ (2006: 135), ESHLEMAN (2008: 395-413), LAUWERS (2013: 331-363).

${ }^{3}$ Mestre (1994: 273-281).

Stylos. 2021; 30 (30); pp. 155-181; ISSN: 0327-8859; E-ISSN: 2683-7900 
labra se democratiza al ser accesible al conjunto de los ciudadanos. De ahí también la relación mercantil que nace en torno a ese aprendizaje: por una parte, el maestro, el sofista, cobra por sus enseñanzas y, por otra, el ciudadano puede saberse autosuficiente ante sus conciudadanos al dominar las armas de la argumentación para hacerlas fértiles en la discusión sobre cualquier tema. De este modo, el conjunto de procedimientos y de recursos de que se sirve el arte de la palabra, si pueden enseñarse, puede también integrarse en la formación del ciudadano.

La retórica en el siglo de oro de Atenas es indisociable de la tribuna política, pero, cuando las circunstancias políticas la enmudecen, el aprendizaje de la retórica, lejos de cesar, se refugia en la escuela del rétor, y adquiere una nueva dimensión. La escuela del rétor se convierte en el lugar donde se aprende retórica no como herramienta imprescindible para lograr una eficiente intervención en la vida pública y social, en la vida de la pólis, sino que se convierte, de forma paulatina y en paralelo a la pérdida de libertad política, en un bien en sí misma, en el valor supremo y elemento clave, nuclear, de la paideía. No obstante, a pesar de que el carácter político de la retórica griega cautivó también a Roma, ${ }^{4}$ en el marco de la tradición y de la literatura griega, una vez perdida la identidad política de la pólis tal como fue concebida en el período clásico, el orador en sus discursos -como explica también Filóstrato- pasó a personificar "los tipos del pobre y el rico, del noble y el tirano, y cuestiones, donde encarnaba a personajes concretos, para las que la historia es guía adecuada". 5

Los nuevos caminos de la práctica retórica en la Segunda Sofística quedan también determinados cuando Filóstrato advierte que los sofistas an-

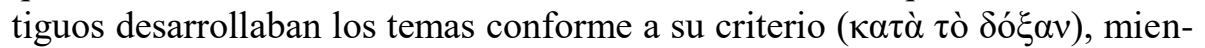

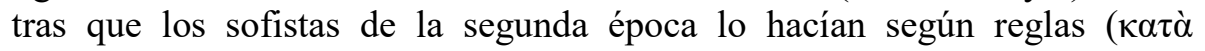

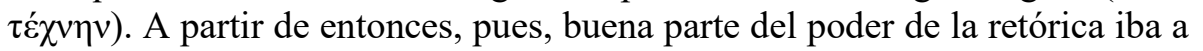
radicar en el dominio de unos códigos, aprendidos y ejercitados en la escuela del rétor. ${ }^{6}$

En su Vidas de los Sofistas Filóstrato describe la relación maestro-

\footnotetext{
${ }^{4}$ Connolly (2007: 144).

${ }^{5}$ Cf. Philostr. VS 482.

${ }^{6}$ Cribiore (2001), Pernot (2003: 126-142).
}

Stylos. 2021; 30 (30); pp. 155-181; ISSN: 0327-8859; E-ISSN: 2683-7900 
discípulo, utilizando esa relación como un elemento esencial para caracterizar a sus sofistas como figuras simbólicas de prestigio e influencia y, sin duda, para cohesionar el conjunto de sofistas como grupo representante de una élite cultural.

\section{UN CATÁLOGO DE SOFISTAS}

En la semblanza de los sofistas, Filóstrato no sigue siempre un mismo patrón ni se atiene a las reglas de composición del género biográfico, pero sí repite algunos indicadores que contribuyen a definir la personalidad de cada sofista. Entre estos ocupa un lugar destacado la referencia a los maestros, de manera que, en muchos casos, señalar de quién el sofista ha recibido su instrucción sirve como carta de presentación. Y, de forma recíproca, el magisterio ejercido es señal inequívoca de autoridad y reconocimiento.

Asimismo, el relato de Filóstrato es una fuente importante para conocer cómo se establecía esa relación maestro-discípulo, puesto que, en algunos casos, advierte que el sofista fue a seguir las lecciones de otro sofista, mientras que, en otras ocasiones, el aprendizaje se produce cuando el sofistamaestro visita una determinada ciudad o se establece temporalmente en ella. Hecho que confirma, sin duda, cómo "durante los primeros siglos del Imperio, aumentó considerablemente la estima de la oratoria deliberativa y la reputación de los sofistas que recorrían el imperio dando muestras de su brillante elocuencia con sus discursos de aparato". ${ }^{7}$ Por ello, Filóstrato también destaca como un signo excepcional de la personalidad y circunstancias de alguien el hecho de permanecer siempre en su lugar de origen, como ocurre con Claudio Eliano, quien solía decir "que nunca se había ausentado de Italia para ir a parte alguna de la tierra, que no había subido a un barco ni conocía el mar" (Philostr. VS. 624).

Otro factor importante, igualmente decisivo en la consideración de los primeros sofistas, fueron los emolumentos percibidos en su condición de maestros, como atestigua Platón en Hipias mayor 282, y Diodoro de Sicilia recuerda a propósito de Gorgias:

${ }^{7}$ GonZÀlez Julià (2009: 160).

Stylos. 2021; 30 (30); pp. 155-181; ISSN: 0327-8859; E-ISSN: 2683-7900 


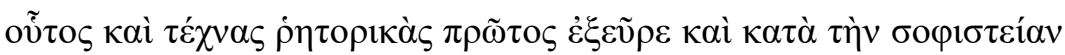

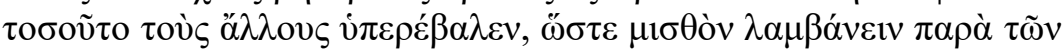

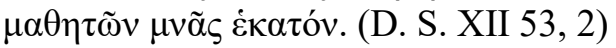

Fue el primero en inventar técnicas retóricas y superó de tal modo a los otros en el arte de los sofistas que llegó a recibir de sus discípulos una retribución de cien minas.

Un servicio caro el de los sofistas ya que una mina equivalía a cien dracmas y cien minas a un talento.

En los primeros siglos de nuestra era, existieron cátedras de retórica en Atenas y en Roma costeadas por la administración tanto del Imperio como municipal, ${ }^{8}$ y las Vidas de los sofistas también contienen información sobre el funcionamiento de dichas cátedras. Filóstrato evoca qué eminentes sofistas las ocuparon, como refiere a propósito de Teódoto de Mélite, quien:

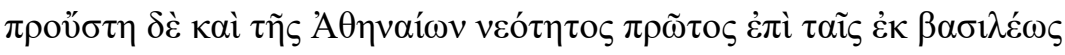
uvpíalc. (Philostr. VS. 566)

Fue el primero en tener a su cargo la formación de la juventud de Atenas con el sueldo imperial de diez mil dracmas.

Pero, igualmente, Filóstrato imputa a la reputación de los sofistas su influencia en la selección de los candidatos. ${ }^{9}$ En este sentido, añade que la intervención de Herodes Ático fue determinante en la concesión de la cátedra a Teódoto:

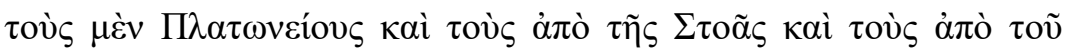

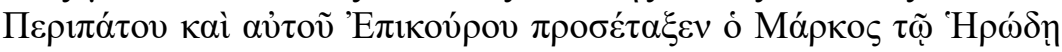

\footnotetext{
${ }^{8}$ Sobre las cátedras de retórica en Atenas, véase Avotins (1975: 313-324). Al parecer, las retribuciones eran bastante distintas entre un tipo u otro de cátedra, como señala WATTS (2006: 24-47).

${ }^{9}$ La relación de los sofistas con el poder es analizada por CôTÉ (2010: 475-502).
}

Stylos. 2021; 30 (30); pp. 155-181; ISSN: 0327-8859; E-ISSN: 2683-7900 


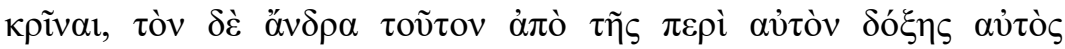

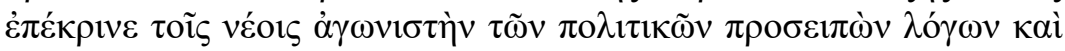

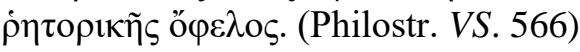

Marco encomendó a Herodes la selección de los filósofos platónicos, estoicos, peripatéticos y epicúreos, pero a este hombre lo eligió él mismo, por el concepto que de él tenía, para educar a los jóvenes, llamándolo maestro en el arte del discurso político y orgullo de la retórica.

En Vidas de los sofistas hay un total de cincuenta y nueve reseñas biográficas, divididas en dos libros y agrupadas en tres categorías distintas de sofistas:

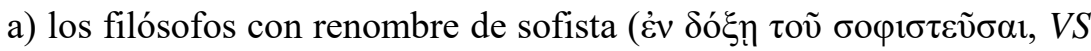
492), cuyos representantes se sitúan en un arco cronológico amplio, desde el s. IV a. C. al s. II d. C. ${ }^{10}$

b) los sofistas de época clásica (s. V-IV a. C.), entre los que incluye a Gorgias, Protágoras, Hipias, Pródico, Polo, Trasímaco, Antifonte, Critias, Isócrates y Esquines; ${ }^{11}$

c) los sofistas de segunda generación -un total de cuarenta y uno-, es decir los de los primeros siglos del Imperio (s. I -III), cuya nómina encabeza el ateniense Esquines (s. IV a. C.), "que afirmamos ser el iniciador de la segunda sofistica" (VS 507). ${ }^{12}$ No obstante, sin solución de continuidad y con un lapso temporal de cuatro siglos, Filóstrato atribuye a Nicetes de Esmirna (s. I d. C.) el logro de haber recuperado el arte de la retórica abandonado en

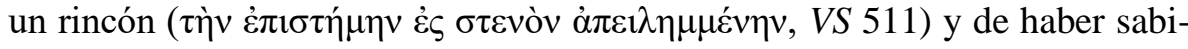

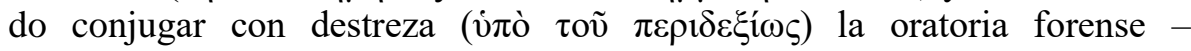
deliberativa y judicial - con el discurso epidíctico gracias a la ornamentación que imprimió al lenguaje forense con la amplificación sofística, porque:

\footnotetext{
${ }^{10}$ Eudoxo de Cnido, León de Bizancio, Días de Éfeso, Carnéades de Atenas, Filóstrato, el egipcio, Teomnesto de Náucratis, Dión de Prusa y Favorino de Arelate.

${ }^{11}$ Cf. Philostr. VS 492-510.

${ }^{12}$ Sobre el papel de Esquines como iniciador de la Segunda Sofística, véase CôtÉ (2005: 389420).
}

Stylos. 2021; 30 (30); pp. 155-181; ISSN: 0327-8859; E-ISSN: 2683-7900 


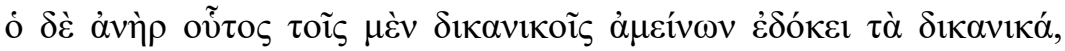

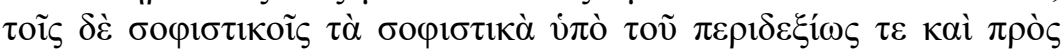

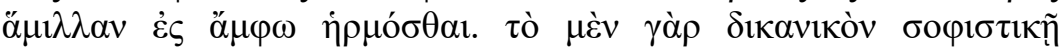

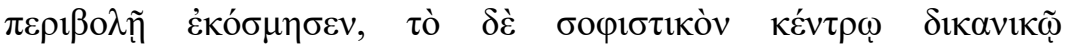

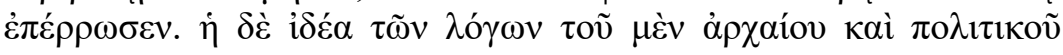

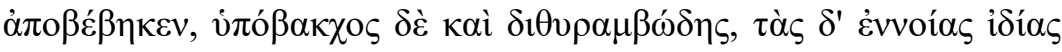

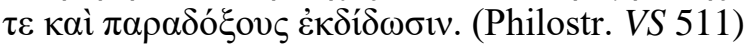

Este hombre, en asuntos jurídicos, parecía mejor que los expertos en oratoria forense y superior a los sofistas, en lo que atañe a la profesión sofística, por adaptarse a ambas modalidades con destreza y por mero deseo de emulación. Pues ornamentaba el lenguaje forense con la amplificación sofística y fortalecía la declamación sofística con el aguijón de la lengua judicial. El estilo de sus discursos está lejos de la antigua elocuencia política; es, en cierto modo, báquico y ditirámbico, ofrece expresiones singulares e insólitas. ${ }^{13}$

La extensión de los relatos en Vidas de sofistas no es uniforme ni, como hemos indicado, siguen un mismo patrón. Sin embargo, el origen y linaje, la fama y la fortuna, los viajes, las relaciones con el poder, el ejercicio de la actividad sofística, los temas de las declamaciones, el estilo oratorio, los cargos públicos desempeñados, los litigios personales y rivalidades en la profesión de orador, la muerte, entre otros tópicos, son algunas constantes que configuran esos relatos, y entre ellas no suele faltar la mención a los maestros ni a la condición de un sofista como "discípulo de", siendo muy pocas las entradas biográficas en las que no hay ninguna referencia a esa relación de magisterio y de aprendizaje, como me propongo analizar ahora centrándome fundamentalmente en los sofistas de segunda generación.

${ }^{13}$ Mestre - Gómez (1998: 333-369).

Stylos. 2021; 30 (30); pp. 155-181; ISSN: 0327-8859; E-ISSN: 2683-7900 


\section{SOFISTAS MAESTROS}

En el conjunto de los sofistas de época imperial -es decir de los que Filóstrato sitúa entre los siglos I y III- solo se omite la referencia a cualquier tipo de vínculo maestro-discípulo -bien sea para indicar el magisterio o el aprendizaje - en cinco ocasiones: Hermógenes de Tarso, Hermócrates de Focea, Varo de Laodicea, Filisco de Tesalia y Heliodoro. Esta omisión queda justificada, con explicaciones de distinta índole, en el resto de la semblanza. Así, por ejemplo, Hermógenes de Tarso, a pesar de haber alcanzado notabilísima fama como sofista, se vio obligado tal vez -apunta Filóstrato- por una enfermedad a abandonar la profesión. ${ }^{14}$ En cambio, de Hermócrates de Focea solo se indica que "puso de relieve la importancia de las dotes naturales"

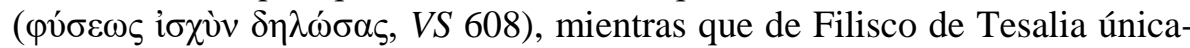
mente Filóstrato constata que ejerció durante siete años la cátedra imperial de retórica de Atenas y la consiguiente exención de impuestos. ${ }^{15}$ La importancia de esa relación discípulo-maestro queda puesta de manifiesto cuando Filóstrato considera indigno denominar sofista a Varo de Laodicea por la pésima calidad de su oratoria y se pregunta:

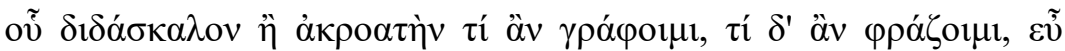

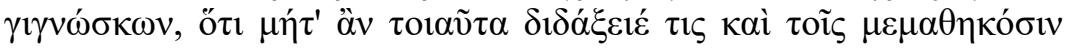

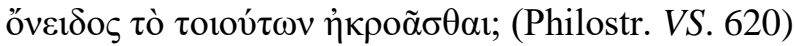

¿Por qué citar a un maestro o discípulo suyo, por qué darlo a conocer, cuando sé bien que nadie podría enseñar cosas tales y que sería motivo de humillación, para los que las aprendieran, el haber oído semejantes enseñanzas?

En otros casos, Filóstrato sí menciona el ejercicio del magisterio, pero no concreta de quién fue maestro el biografiado, y plasma de formas diversas esa alusión a la actividad docente. A veces, Filóstrato se limita a mencionar

\footnotetext{
${ }^{14}$ Cf. Philostr. VS 577-578.

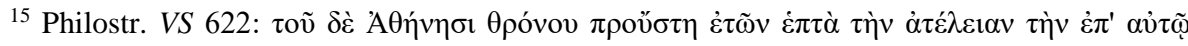

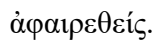

Stylos. 2021; 30 (30); pp. 155-181; ISSN: 0327-8859; E-ISSN: 2683-7900 
el desempeño de una cátedra, imperial o municipal, fuera en Atenas, fuera en Roma, y, en consecuencia, queda implícita esa docencia ejercida. Así lo indica a propósito de Pausanias de Cesarea, que había ocupado las cátedras de retórica de Roma y de Atenas; ${ }^{16}$ y también a propósito de Evodiano de Esmirna, quien llegó hasta Roma para ocupar allí la cátedra de retórica como "recompensa por la calidad de su elocuencia" ( $\tau \grave{\alpha} \delta \dot{\varepsilon} \tau \tilde{\eta} \varsigma \varphi \omega v \tilde{\eta} \varsigma \tilde{\alpha} \theta \lambda \alpha \dot{\varepsilon} \varsigma \tau \grave{\eta} v$

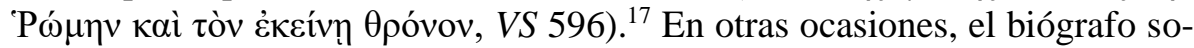
lo advierte que los discípulos de un sofista fueron numerosos: Heraclides de Licia era competente en la invención y en la declamación y, a pesar de haber sido expulsado de la cátedra de Atenas por diversas intrigas y rivalidades con otros sofistas, una vez establecido en Esmirna, hasta esta ciudad acudieron para seguir sus enseñanzas jóvenes de Jonia, Caria, Lidia y Frigia, pero igualmente -señala Filóstrato- atraía "a la juventud estudiosa de Europa, a los jóvenes de Oriente, a muchos egipcios que lo habían oído hablar" (ò $\delta \dot{\varepsilon}$

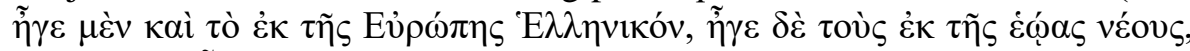

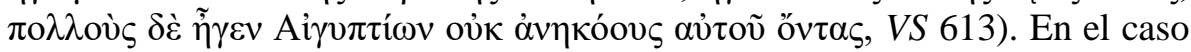
de Quirino de Nicomedia la evocación de la actividad magistral es muy escueta, puesto que el biógrafo se limita a consignar que era "excelente su natural para recibir enseñanzas y aún mejor para transmitirlas, pues no cultivaba solo su memoria, sino también la claridad de lenguaje" ( $\varphi v ́ \sigma ı \varsigma ~ \grave{\alpha} \gamma \alpha \theta \grave{\eta}$

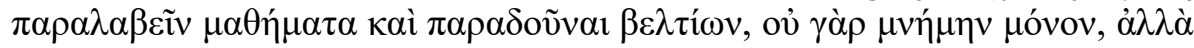

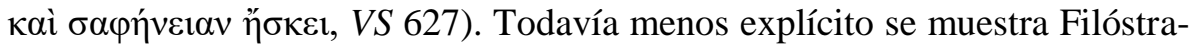
to en relación a Onomarco de Andros -totalmente desconocido, salvo por haber sido incluido en el elenco filostrateo-, de quien solo dice que "ejercía la enseñanza en la época en que Adriano y Cresto enseñaban en Atenas"

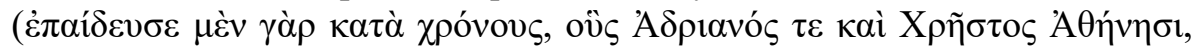
VS 598). Esta referencia nos permite constatar que el magisterio de los sofistas sirve al biógrafo como referencia cronológica relativa en el interior de su

\footnotetext{
${ }^{16}$ Cf. Philostr. VS 594.

${ }^{17}$ Tampoco se menciona ningún discípulo de Aspasio de Ravena, que estuvo igualmente al frente de la cátedra de Roma: "cuando joven, altamente reputado, ya viejo, con críticas por no

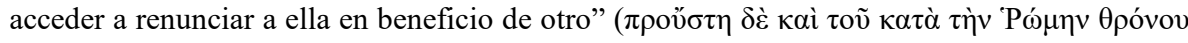

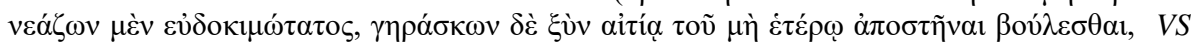

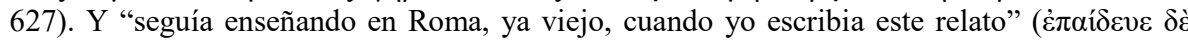

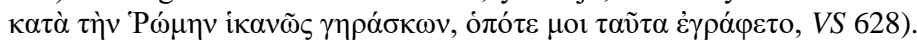

Stylos. 2021; 30 (30); pp. 155-181; ISSN: 0327-8859; E-ISSN: 2683-7900 
obra.

El anonimato de los discípulos puede ser debido también a las propias características de la oratoria del maestro, como sucedía -según Filóstratocon Fénix de Tesalia, que era "mejor en la invención del discurso que en la

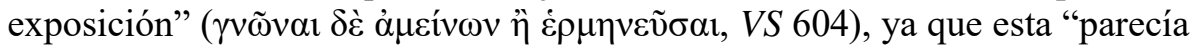

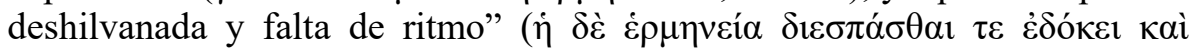
$\dot{\rho} v \theta \mu о \tilde{~ \alpha}(\varphi \varepsilon \sigma \tau \eta \kappa \varepsilon ́ v \alpha 1$, ibidem); y, en consecuencia:

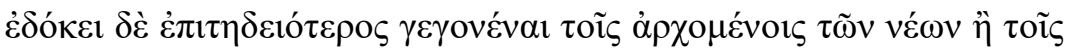

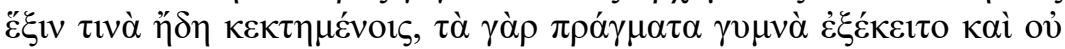

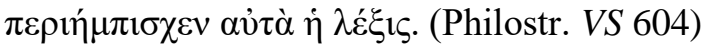

Pasaba por ser más adecuado para los jóvenes que empezaban, que para los que tenían ya alguna formación, porque exponía los temas escuetamente, sin que sus palabras los engalanaran.

Por otra parte, las Vidas de los sofistas evidencian cómo la escuela en el mundo grecorromano reservaba un espacio preeminente a la retórica en la formación no solo de futuros oradores-sofistas, sino de los jóvenes pertenecientes a las élites del Imperio, porque el $\lambda$ ó ${ }^{\circ} \varsigma$-palabra, discurso- era entonces una herramienta imprescindible para obtener y mantener una posición elevada dentro de la sociedad, de modo que la Segunda Sofística puede y debe ser considerada un fenómeno social que trasciende el ámbito de la práctica oratoria y de la escuela. ${ }^{18}$ Ello explica que un sofista como Cresto de

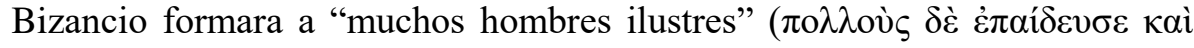

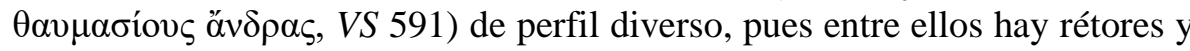
sofistas, pero también poetas, magistrados, secretarios imperiales, miembros del Consilium imperial, filósofos, sacerdotes, reseñando los nombres de los más insignes ("Hipódromo, el sofista, Filisco, Iságoras el poeta trágico, rétores eminentes cual Nicomedes de Pérgamo y Aquila, el originario de Galacia oriental, Aristéneto de Bizancio, filósofos reputados, como Calesero de Atenas, Sospis, sacerdote al servicio del altar", ibidem), aunque añade que hubo

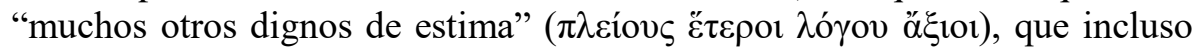

${ }^{18}$ WeBB (2017: 139-153).

Stylos. 2021; 30 (30); pp. 155-181; ISSN: 0327-8859; E-ISSN: 2683-7900 
cuantifica:

Tenía cuando enseñaba, en época del sofista Adriano, un centenar de alumnos que pagaban por sus enseñanzas.

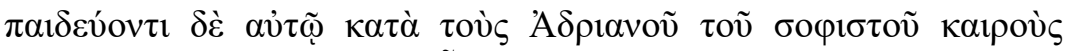

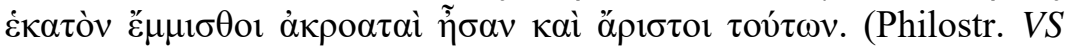
591)

El precio y aprecio de la instrucción retórica puede deducirse también del testimonio filostrateo sobre Damiano de Éfeso, un hombre famosísimo, de ilustres antepasados e inmensa riqueza por la que sentía escaso apego y usaba - a juicio del biógrafo- de modo conveniente ( $\alpha \alpha \lambda \tilde{\omega} \varsigma$ ), por ejemplo, formándose con los mejores sofistas:

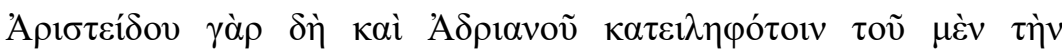

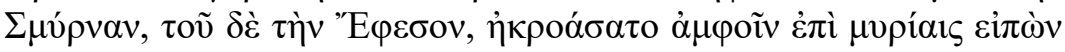

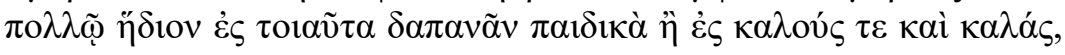
$\omega ̋ \sigma \pi \varepsilon \rho$ हैंvot. (Philostr. VS 605)

Así, cuando Arístides y Adriano señoreaban con su arte, uno, Esmima, otro, Éfeso, oyó las lecciones de ambos, mediante el pago de diez mil dracmas, afirmando que era más placentero gastar en tales amantes que en hermosos mancebos o doncellas, como otros hacían.

El caché de estos profesionales de la palabra era elevado, aunque Filóstrato no deja de señalar también su altruismo. Del mismo Damiano de Éfeso subraya que ofrecía gratis sus servicios en los tribunales a quienes se hallaban en situación apurada, pero igualmente en su actividad como maestro:

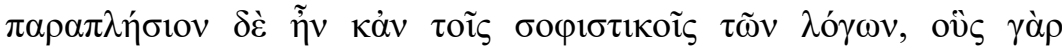

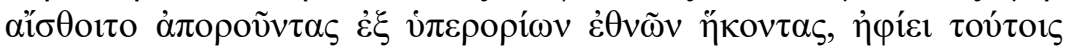

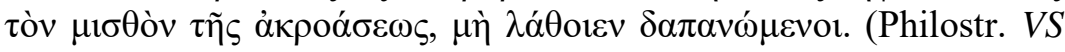
606)

Stylos. 2021; 30 (30); pp. 155-181; ISSN: 0327-8859; E-ISSN: 2683-7900 
Algo semejante ocurría con sus lecciones de sofística, pues a los que veía, llegados de tierras lejanas, escasos de recursos, les perdonaba la remuneración por su enseñanza para que no gastaran en exceso sin advertirlo.

También Filóstrato da noticia de que Escopeliano, a pesar de congregar en Esmirna a jóvenes llegados de todos los puntos del Imperio para seguir sus enseñanzas, no era "codicioso" ( $\varphi$ i $о \chi \rho \eta ́ \mu \alpha \tau o \zeta, ~ V S ~ 519)$, pues "daba sus clases de declamación a cambio de emolumentos que eran diferentes de

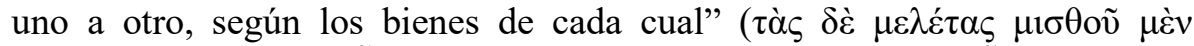

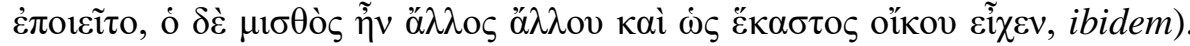
$\mathrm{Y}$ ese mismo desprendimiento se materializa en las palabras de Cresto de Bizancio cuando pidió que se suspendiera la embajada enviada al emperador solicitando para él la cátedra de Atenas, en la época en que Adriano ocupaba la de Roma, diciendo: "Diez mil dracmas no hacen a un hombre" (ov̉ $\chi \alpha i$

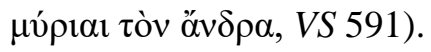

\section{SOFISTAS DISCÍPULOS}

Mucho más claro es Filóstrato en señalar de quién fue discípulo el sofista cuyo perfil está redactando, siendo muy contadas las omisiones de dicha información. En primer lugar, puede observarse que muy a menudo se menciona a más de un maestro, bien sea para indicar momentos distintos en la formación del sofista, o diversidad de lugares en que este recibió instrucción, bien sea para destacar incluso la simultaneidad en frecuentar las lecciones de diversos maestros.

Así, Rufo de Perinto habría sido -según Filóstrato- discípulo

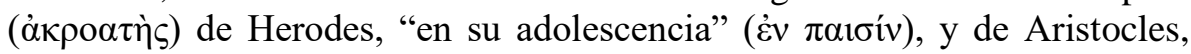

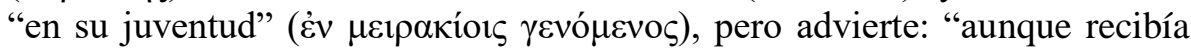
de este grandes elogios, él se enorgullecía, más bien, de Herodes, llamándolo

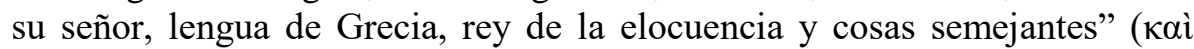

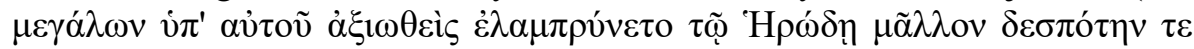

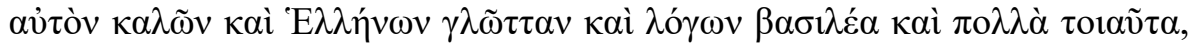
VS 598).

Stylos. 2021; 30 (30); pp. 155-181; ISSN: 0327-8859; E-ISSN: 2683-7900 
Alejandro de Seleucia tuvo como maestros a Favorino y a Dionisio este, tal vez, en Mileto-, pero Filóstrato precisa que su verdadero maestro fue - probablemente en la Galia- Favorino, "de quien adquirió, en especial,

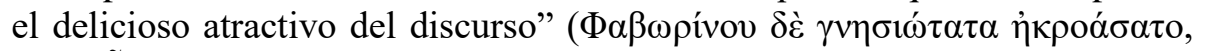

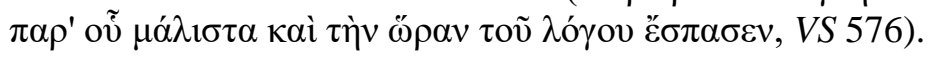

Filóstrato señala que Apolonio de Náucratis -sofista desconocido, por otra parte- fue discípulo de los sofistas Adriano y Cresto, pero advierte que

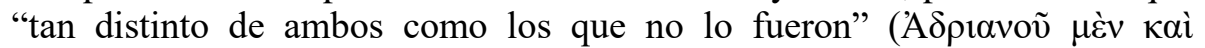

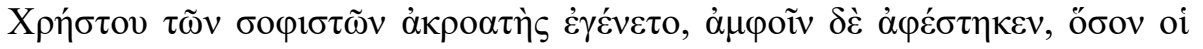
$\mu \eta ̀ ~ \grave{\alpha} \kappa o v ́ \sigma \alpha \nu \tau \varepsilon \varsigma, V S$ 600). Bien distinto fue -según el biógrafo- el resultado del doble aprendizaje del tracio Atenodoro, sofista de ilustres antepasados, pero "por sus maestros y educación, el más conspicuo de los estudiantes

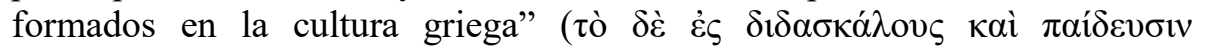

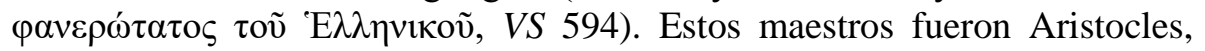

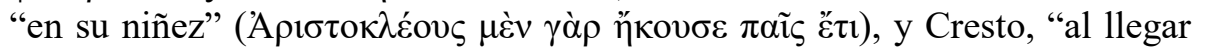

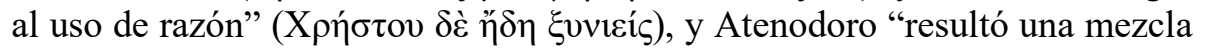
de ambos, porque en sus discursos reunía la elegancia ática y la ampulosidad

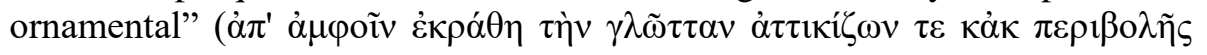

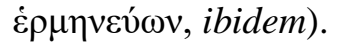

Asimismo cabe destacar el recuerdo especial de Filóstrato hacia sus propios maestros: Proclo de Nàucratis, al que incluye en su lista-dice- por

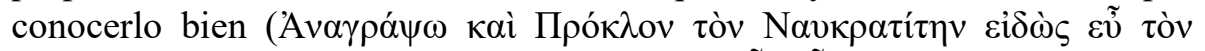

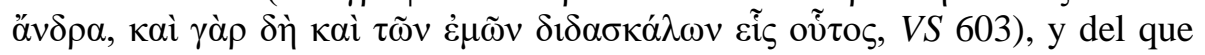
refiere era, a su vez, discípulo de Adriano; y también Damiano, al que juzga mejor sofista que orador forense, pero más experto abogado de lo que suele ser un sofista, pero destaca ante todo su generosidad en compartir su saber incluso después de retirarse de la escena pública:

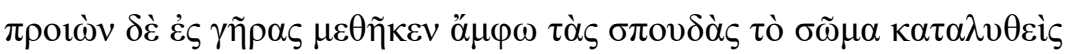

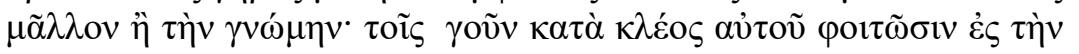
"Е

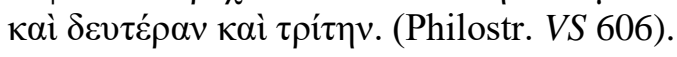

Cuando se iba haciendo viejo, dejó ambas actividades, desgastado su cuerpo mas que su entendimiento. Permitía visitarlo a los que venían

Stylos. 2021; 30 (30); pp. 155-181; ISSN: 0327-8859; E-ISSN: 2683-7900 
a Éfeso por causa de su fama; también a mí me concedió la merced de una visita, primero, y una segunda y una tercera, después.

Muy elogioso se muestra Filóstrato -en un alarde, no obstante, de falsa modestia y manifestación de autoestima- con Hipódromo de Tesalia, de quien dice fue su maestro y reconoce que le había dado muchos consejos en su preparación. Por ello, el biógrafo recuerda que, cuando era todavía un joven de veinte años, tras pronunciar un elogio en Olimpia, los griegos solicitaron que también Hipódromo hablara, pero no lo hizo y se limitó a responder: "No saldré a competir contra los que son mis propias entrañas" ("oủк

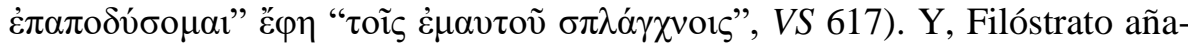
de:

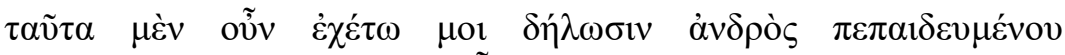

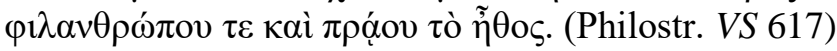

Téngase lo dicho como prueba, en mi opinión, de su calidad de hombre educado, condescendiente y de carácter bondadoso.

Asimismo, las Vidas de los sofistas muestran una significativa acumulación de discípulos en determinados sofistas, hecho que constituye un indicio relevante de la propia reputación del sofista-maestro por su elocuencia, como es el caso particular de Iseo (s. I d. C.), Adriano de Tiro y, muy especialmente, Herodes Ático.

En el relato sobre Iseo, un sofista muy elogiado también por Plinio, ${ }^{19}$

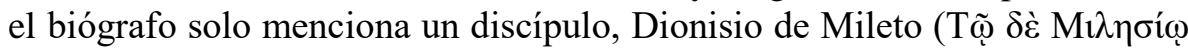

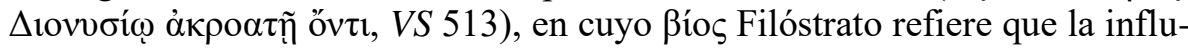
encia del maestro fue muy positiva, pues la naturalidad y falta de artificio caracterizaban su estilo, que él mismo trasladaba a sus discípulos:

\footnotetext{
${ }^{19}$ Plin. Ep. 2.3.1: Magna Isaeum fama praecesserat, maior inuentus est. Summa est facultas copia ubertas; dicit semper ex tempore, sed tamquam diu scripserit. Sermo Graecus, immo Atticus; praefationes tersae graciles dulces, graues interdum et erectae. Cf. también Ep. 5.20.
}

Stylos. 2021; 30 (30); pp. 155-181; ISSN: 0327-8859; E-ISSN: 2683-7900 


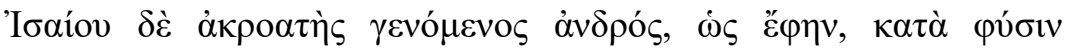

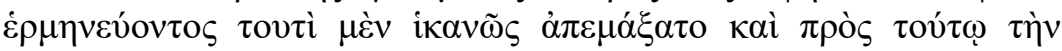

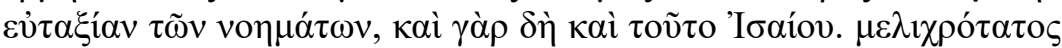

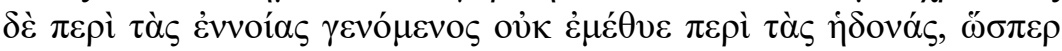

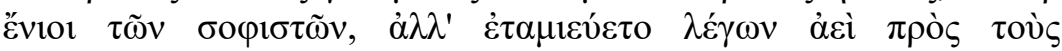

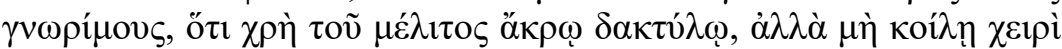

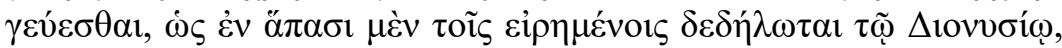

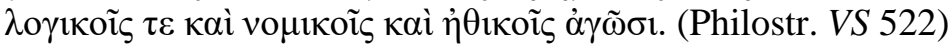

Fue discípulo de Iseo, hombre, como he dicho, que hablaba con naturalidad, y se ajustó notablemente a este modelo y, además, a su secuencia ordenada de pensamientos, pues también esto es, en efecto, propio de Iseo. Aunque ponía dulzura de miel en sus reflexiones, no se embriagaba en los efectismos declamatorios como algunos de los sofistas, sino que los usaba con parquedad, advirtiendo siempre a sus alumnos que había que degustar la miel con la punta del dedo, no con el hueco de la mano, según aparece probado en todos los discursos pronunciados por Dionisio.

A partir de las biografías de Loliano de Éfeso y de Marcos de Bizancio, sabemos que ambos sofistas también recibieron su instrucción de Iseo, de quien el de Éfeso sacó sus dotes para la improvisación -"improvisaba al

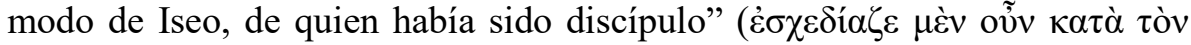

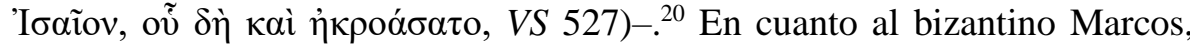
también este aprendió de Iseo a expresarse con naturalidad, que "ornamentó,

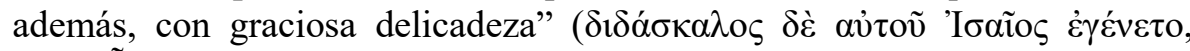

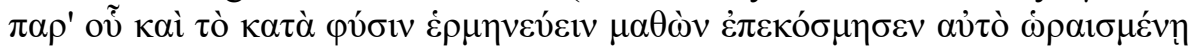

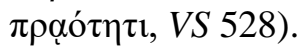

La nómina de discípulos de Adriano es amplia (Pólux de Náucratis, Apolonio de Náucratis, Apolonio de Atenas, Proclo de Náucratis, Damiano

\footnotetext{
${ }^{20}$ Según Filóstrato, la retribución percibida por Loliano, que también enseñaba ejercicios

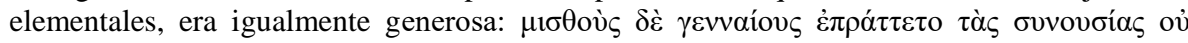

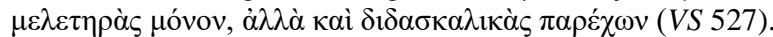

Stylos. 2021; 30 (30); pp. 155-181; ISSN: 0327-8859; E-ISSN: 2683-7900 
de Éfeso, ${ }^{21}$ Antípatro de Hierápolis, Heraclides de Licia, ${ }^{22}$ Quirino de Nicomedia), y la huella que dejó el fenicio en ellos es variada. ${ }^{23}$ Así, Filóstrato considera que Pólux no era demasiado sencillo ni en exceso elevado, aunque lo estima inferior a su maestro, al afirmar: "dista, por igual, de sus más altas cualidades y de sus imperfecciones" y "solo hay algunas gotas de almíbar

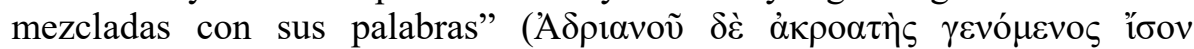

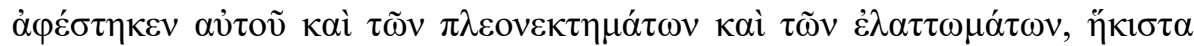

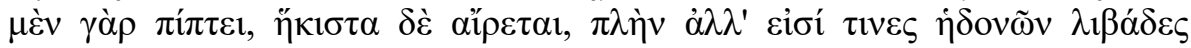

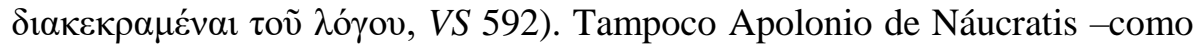
ya hemos indicado- siguió los pasos de su maestro, ${ }^{24}$ y lo mismo afirma Filóstrato a propósito de Apolonio de Atenas, a quien juzga "nada despreciable

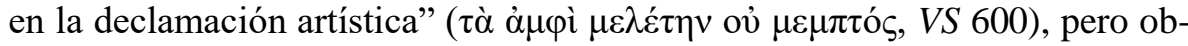
serva que el ateniense ganaría en calidad si siguiera más de cerca el estilo de Adriano:

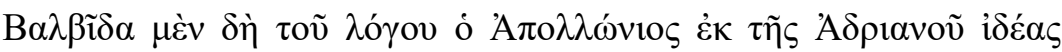

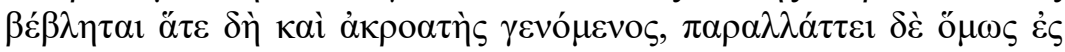

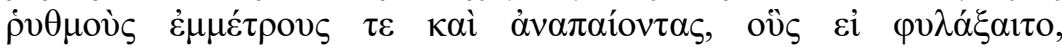

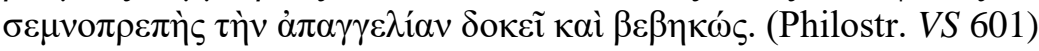

Toma Apolonio de punto de arranque de su elocuencia el estilo de Adriano, como discípulo suyo que fue, pero, sin embargo, se desvía y da en ritmos poéticos de cadencia anapéstica; mas, si se guarda de tales artificios, parece en sus discursos severamente digno, solemne en su andadura.

\footnotetext{
${ }^{21}$ Filóstrato solo menciona a los maestros de Damiano, pero no refiere nada sobre su estilo ni sobre las enseñanzas recibidas.

${ }^{22}$ Además de Adriano, también instruyeron a Heraclides otros sofistas como Cresto, Aristocles y quizás Herodes, pero Filóstrato no vincula de forma específica a ninguno de sus maestros el prestigio ni la competencia del sofista de Hierápolis, "sencillo en los alegatos forenses,

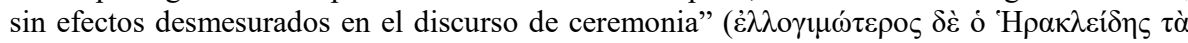

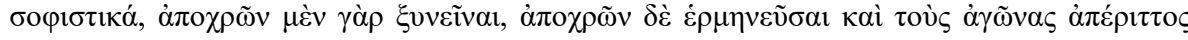

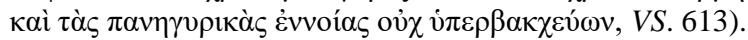

${ }^{23}$ Sobre la personalidad de este sofista, véase CAMPANILE (2003: 245-273).

${ }^{24}$ Cf. Philostr. VS 600; supra.
}

Stylos. 2021; 30 (30); pp. 155-181; ISSN: 0327-8859; E-ISSN: 2683-7900 
En cuanto a Proclo de Náucratis, Filóstrato valora positivamente la enseñanza de Adriano sobre este sofista egipcio, puesto que, a pesar de expresarse con sencillez en sus discursos, en "la acumulación de pensamientos

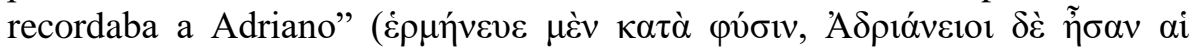

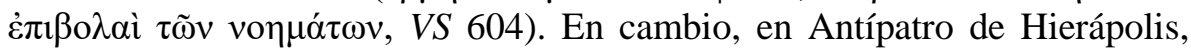
Adriano fue, a juicio de Filóstrato, el maestro de menor influencia en él, puesto que su estilo revela claramente la influencia de otros instructores:

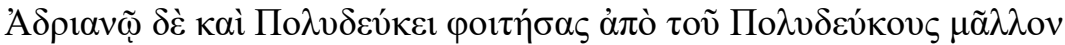

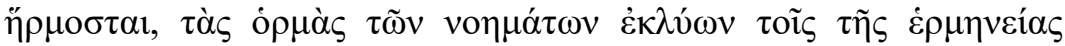


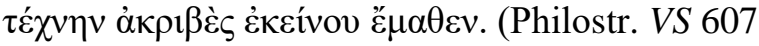

Frecuentó las clases de Adriano y Pólux, pero armoniza mejor con los modos de Pólux y, así, disminuye el vigor de sus pensamientos con los ritmos de la exposición. Oyó también las lecciones de Zenón de Atenas y aprendió de él lo más alambicado de la profesión.

Sobre la huella del magisterio de Adriano en Quirino de Nicomedia, sofista "brioso y vehemente y diestro en conmover a los que lo escuchan,

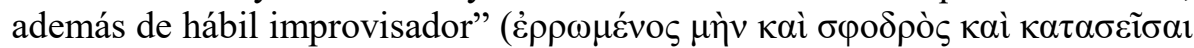

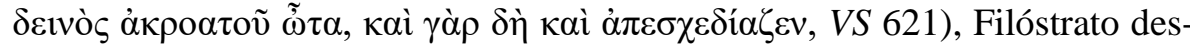
taca el carácter crítico del sofista respecto a las enseñanzas recibidas:

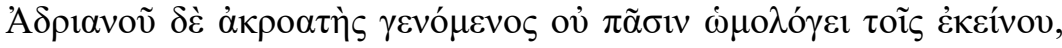

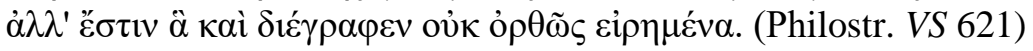

Fue discípulo de Adriano, pero no se mostraba conforme con todos sus escritos, sino que había cosas que eliminaba por mal dichas.

Pero, sin duda alguna, entre los sofistas de su elenco, es Herodes Ático a quien Filóstrato atribuye un mayor magisterio: ${ }^{25}$ Teódoto de Atenas,

\footnotetext{
${ }^{25}$ La abundante bibliografía sobre la figura y personalidad de Herodes Ático en la obra de Filóstrato es recogida por STRAZDINS (2019: 238-264).
}

Stylos. 2021; 30 (30); pp. 155-181; ISSN: 0327-8859; E-ISSN: 2683-7900 
Aristocles de Pérgamo, Arístides, Adriano de Tiro, Ptolomeo de Náucratis, Cresto de Bizancio, Pausanias de Cesarea y Onomarco de Andros. ${ }^{26}$

El ateniense Teódoto, por ejemplo, fue discípulo de Loliano, pero "no

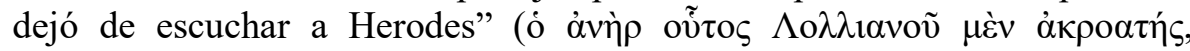

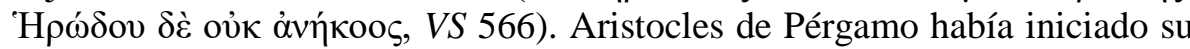
formación en el ámbito de la filosofía "desde la niñez a la adolescencia", pero se cambió a la enseñanza sofística y asistió, en Roma, a las lecciones de

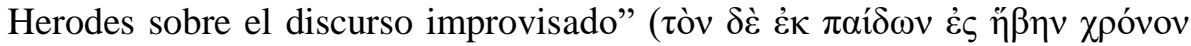

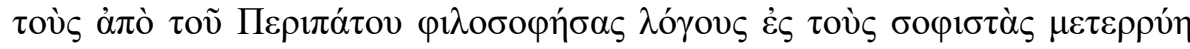

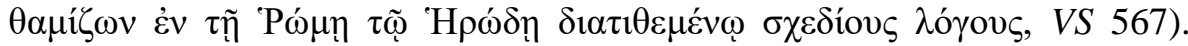
Arístides siguió las enseñanzas de Herodes en Atenas cuando este sofista estaba en su madurez. ${ }^{27}$ Ptolomeo de Náucratis, a pesar de ser discípulo de Herodes, según el parecer de Filóstrato, no emuló a su maestro, sino que se dejó atraer por el estilo de Polemón, algunos de cuyos rasgos estilísticos se reproducen en la elocuencia de Ptolomeo:

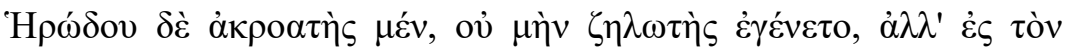

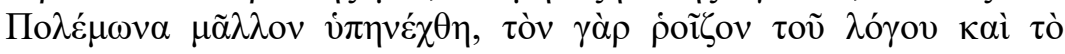

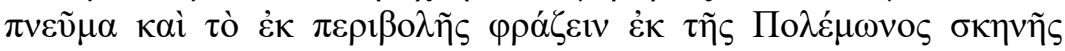

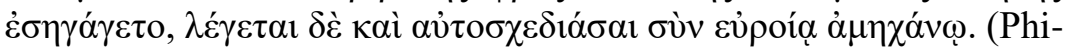
lostr. VS 595)

...la impetuosidad y el vigor de sus palabras, así como la expresión profusamente ornamentada, son rasgos de estilo que había tomado del acervo de Polemón, y se dice también que improvisaba con fluidez inagotable.

En cambio, el bizantino Cresto sí que seguía, en opinión de Filóstrato, los recursos de Herodes, aunque sin alcanzar la calidad del maestro. No obstante, el biógrafo justifica este déficit por la muerte del sofista:

${ }^{26}$ Filóstrato pone en duda que Heraclides de Licia fuera instruido por Herodes; cf. VS 615.

${ }^{27}$ Refiere Filóstrato que Arístides en Pérgamo siguió las enseñanzas de Aristocles cuando este

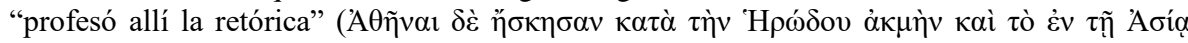

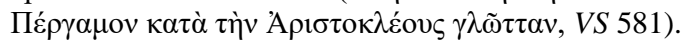

Stylos. 2021; 30 (30); pp. 155-181; ISSN: 0327-8859; E-ISSN: 2683-7900 


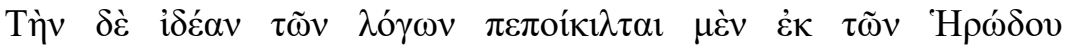

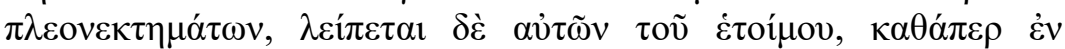

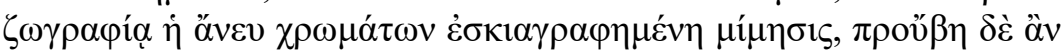

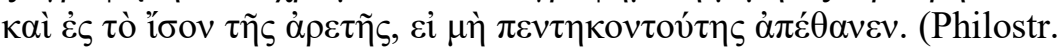
VS 592)

Dio variedad al estilo de su elocuencia con el uso de los mejores recursos de Herodes, pero les son inferiores en viveza, lo mismo que en pintura la imagen dibujada solo, sin el complemento del color, pero hubiera llegado, incluso, a igualar su perfección, de no haber muerto a los cincuenta años.

Al hablar de Onomarco de Andros, Filóstrato contrapone la declamación aticista a la de estilo asianista, pero, a su juicio, el estilo jónico de este sofista no llega a empañar la impronta de Herodes en la formación de Onomarco, quien por proximidad geográfica "se contagió" (๕̌ $\sigma \pi \alpha \sigma \varepsilon)$ de la oratoria practicada en Éfeso, estropeando "la calidad de su elocuencia, pero la acumulación de pensamientos, indeciblemente grata, era como la de Hero-

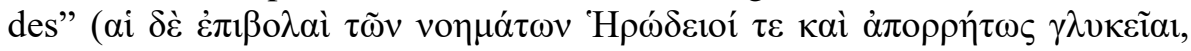
VS 598).

Por otra parte, Filóstrato cifra la importancia del magisterio de Herodes no solo por el número elevado de discípulos que le atribuye entre sus biografiados, sino por la calidad y especificidad en el modo de impartirlo y su método de enseñanza, como parece deducirse de las dos alusiones, en las $V i$ das de los sofistas, al Clepsidrio. ${ }^{28} \mathrm{El}$ biógrafo designa con este término a un selecto grupo de discípulos de Herodes, como explica en su semblanza de Adriano:

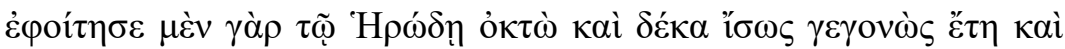

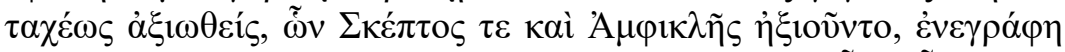

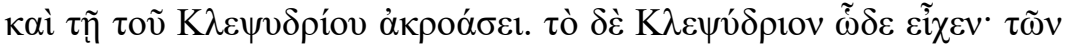

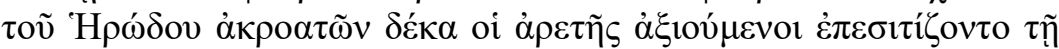

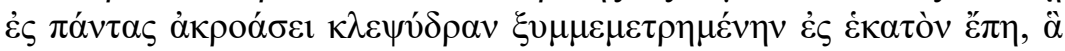

${ }^{28}$ Sobre este grupo selecto de alumnos, véase RAIMONDI (2010: 288).

Stylos. 2021; 30 (30); pp. 155-181; ISSN: 0327-8859; E-ISSN: 2683-7900 


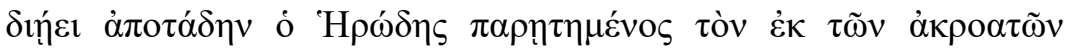

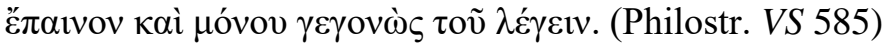

Empezó a asistir a las clases de Herodes cuando tenía unos dieciocho años, en seguida gozó de la misma consideración que Escepto y Anficles, y fue inscrito para la clase del Clepsidrio que consistía en lo siguiente: de los discípulos de Herodes, diez, los de mayores méritos, asistían, además de a las clases comunes a todos, a una sesión especial que duraba tanto como tarda una clepsidra en medir el rato que se emplea en recitar cien versos y en la que Herodes hablaba todo el tiempo sin permitir el aplauso de sus oyentes, pendiente solo de lo que iba diciendo.

Por lo tanto, el hecho de que Filóstrato se refiera al Clepsidrio solo en relación al magisterio de Herodes sobre Adriano de Tiro y Pausanias de Cesarea, parece que es con la intención de subrayar el talento oratorio de ambos sofistas, aunque considera que no alcanzaron los mismos resultados. Porque, en el caso de Adriano, evoca las elogiosas palabras del propio Herodes tras haber oído al de Tiro pronuciar un discurso improvisado:

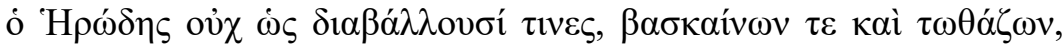

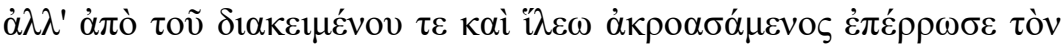

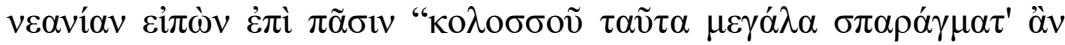

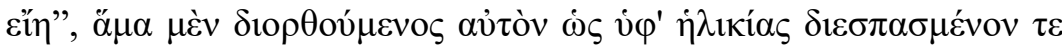

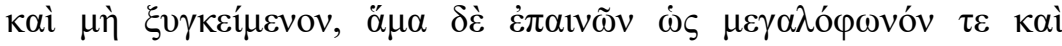
$\mu \varepsilon \gamma \alpha \lambda \sigma \gamma v \omega ́ \mu \sigma \alpha \alpha$. (Philostr. VS 586)

Herodes, tras escucharlo, no como dicen insidiosamente algunos con sentimientos de celos y de burla, con su normal disposición benévola, animó al muchacho, diciéndole por último: "Estos podrían ser los grandes fragmentos de un coloso". Y, al tiempo que corregía lo disperso y poco trabado de su discurso, cosa natural a su edad, ensalzaba su lenguaje elevado y la nobleza de sus pensamientos.

En cambio, en opinión de Filóstrato, el de Cesarea, a pesar de su ma-

Stylos. 2021; 30 (30); pp. 155-181; ISSN: 0327-8859; E-ISSN: 2683-7900 
estro, no gozó del mismo éxito que otros condiscípulos y quizás sea señal de ello que su biografía no contenga referencia alguna a la enseñanza impartida por Pausanias, que ocupó la cátedra de Roma y la de Atenas, a ningún otro célebre sofista incluido en el catálogo filostrateo:

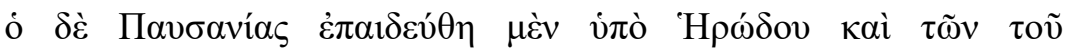

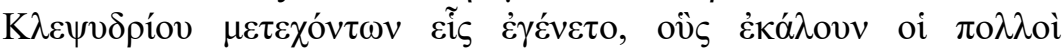

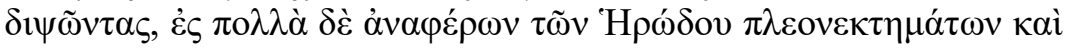

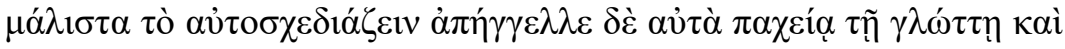

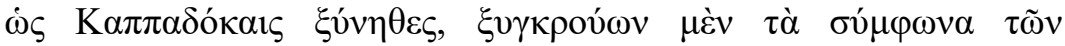

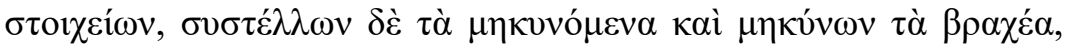

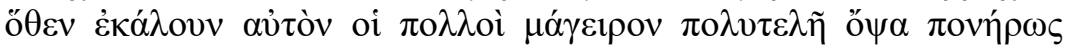

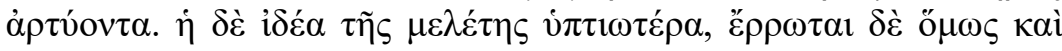

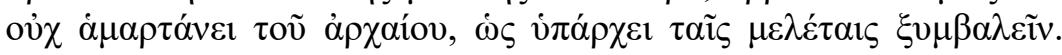
(Philostr. VS 586)

Fue educado por Herodes y era uno de los componentes del grupo del Clepsidrio, a los que la gente solía llamar "los sedientos", pero, aunque se elevó hasta poseer muchos de los mejores recursos de Herodes y, en especial, la técnica de la improvisación, se expresaba con lengua torpe, como es usual entre los capadocios, tropezando en las consonantes, abreviando los sonidos largos y alargando los breves, por lo que la gente solía llamarlo pésimo cocinero de manjares exquisitos. El estilo de su declamación es muy lento, pero, sin embargo, tiene vigor y no falla en los toques de antigüedad, como se puede colegir de sus declamaciones.

\section{A MODO DE CONCLUSIÓN}

El elevado número de referencias intertextuales sobre la interacción docentediscente es un elemento significativo de los relatos biográficos, porque con ella Filóstrato establece vínculos internos en el conjunto de los biografiados que contribuyen de manera eficaz a presentar a los sofistas de época imperial como grupo de élite erudito, de pepaideuménoi, cohesionado por el conoci-

Stylos. 2021; 30 (30); pp. 155-181; ISSN: 0327-8859; E-ISSN: 2683-7900 
miento de las reglas retóricas y por el ejercicio de la oratoria en sus distintas modalidades. ${ }^{29}$

Esta obra de Filóstrato constituye un vasto entretejido que, desde diversos aspectos, deja a la vista la trama de la relación entre maestros y discípulos, y de estos a la reformulación del magisterio de aquellos, que es nuevamente legado en la formación de nuevos discípulos. Las Vidas de los sofistas ofrecen una visión del maestro y de la enseñanza en ámbito grecolatino, ceñida a un grupo limitado, deliberadamente seleccionado por Filóstrato, pues siempre se han señalado en su catálogo también algunas notables ausencias de hombres que ejercieron la profesión de sofista, como es el caso de Luciano de Samosata, si bien es cierto que precisamente el samosatense no parece haberse dedicado al magisterio. ${ }^{30}$

A partir del texto de Filóstrato pueden establecerse secuencias de tres, e incluso de cuatro, generaciones de hombres dedicados al oficio de oradorsofista que transmiten su saber, es decir, enseñan a ser y a actuar a través de la palabra, del $\lambda$ ó $\gamma$ o $\varsigma$, instruyendo en el arte del bien decir: Iseo-LolianoFilagro-Fénix, Nicetes-Escopeliano-Polemón, Herodes-Adriano-Proclo, Herodes-Cresto-Heraclides, Adriano-Pólux-Antípatro, Herodes-Arístides- Damiano, y así sucesivamente.

El relato de Filóstrato nada tiene que ver con un tratado de retórica, pero ofrece numerosos apuntes sobre cómo podía aprenderse este arte de la palabra no solo en aspectos formales, en tipos de oratoria, sino ante todo sobre cómo se establecía la relación maestro-discípulo. En numerosas ocasiones, el biógrafo alude a aspectos meramente materiales como los honorarios del maestro, el modo de pago de los discípulos, o las condiciones de la instrucción misma. En este sentido, Filóstrato recuerda alguna particularidad del aprendizaje con uno de sus maestros, Proclo de Náucratis, con referencia a aspectos crematísticos, pero también de disciplina, destacando además el papel de la biblioteca en la formación de los jóvenes, esencial en el mundo

${ }^{29}$ BORG (2004: 157-178).

${ }^{30}$ Como señala HENDERSON (2011: 23-35), Filóstrato muestra las normas de la élite social e intelectual que determinaron el prestigio e impacto social de esta, aunque también hubo oradores que utilizaron conscientemente algunos de los recursos del sofista en una causa antisofista, imitando el comportamiento de los sofistas profesionales pero subordinándolo a otros valores. Cf. GómEz (2003: 277-284).

Stylos. 2021; 30 (30); pp. 155-181; ISSN: 0327-8859; E-ISSN: 2683-7900 
libresco de la Segunda Sofística:

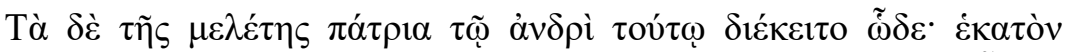

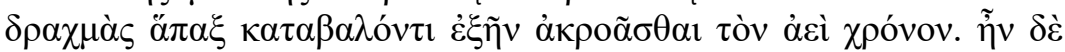

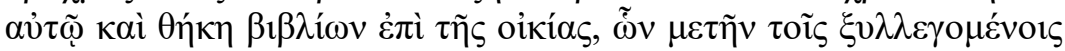

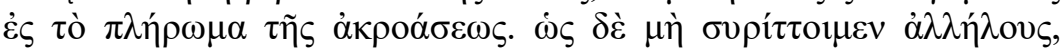

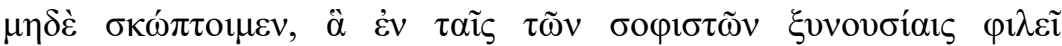

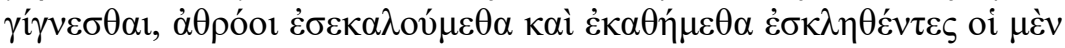

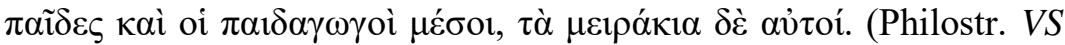
604)

Unas normas regían la escuela de este sofista. Al que pagaba cien dracmas de una vez le estaba permitido asistir al ciclo completo de enseñanzas. Tenía una biblioteca en su casa de la que podían servirse los alumnos para complementar su instrucción. A fin de que no intercambiásemos rechiflas e insultos, cosa que suele ocurrir en las escuelas de los sofistas, nos llamaban a todos a la vez y nos sentábamos, tras acudir a la llamada, los niños primero, los pedagogos en medio y los jóvenes por separado.

Desde el punto de vista del lenguaje, podemos observar también cómo Filóstrato designa, en general, con el verbo $\pi \alpha 1 \delta \varepsilon v ́ \omega$ la acción del maestro, mientras que la labor del discípulo consiste en escuchar y poner en práctica,

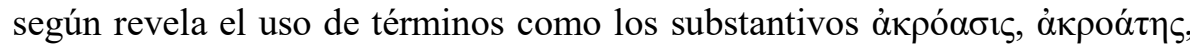

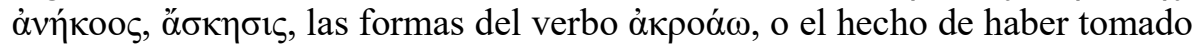
lección con alguien por haberlo oído en alguna de sus declamaciones públicas $\left(\mu \varepsilon \lambda \varepsilon^{\prime} \tau \alpha \mathrm{l}\right)$.

El valor de la instrucción oratoria que pueden ofrecer los sofistas de Filóstrato a quienes quizás no van a dedicarse de forma exclusiva a la práctica del discurso epidíctico, es perceptible en las frecuentes referencias a la calidad y al modo de ejecución del discurso de un determinado sofista, distinguiendo entre la dimensión forense de su actividad y la meramente declamatoria, de exhibición pública.

Por otra parte, muy a menudo Filóstrato apunta también que la oratoria, incluso en su dimensión de exhibición pública, no puede ser solo un me-

Stylos. 2021; 30 (30); pp. 155-181; ISSN: 0327-8859; E-ISSN: 2683-7900 
ro artificio de palabras, un juego extravagante del lenguaje, como revela la iteración del término vó $\mu \alpha$. Así, el biógrafo destaca en el estilo de sus sofistas "la secuencia ordenada de pensamientos", de Dionisio de Mileto (

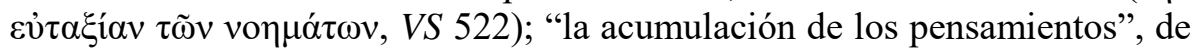

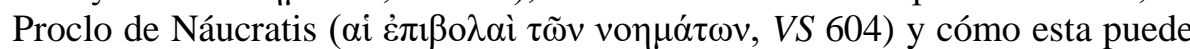
ser igualmente grata cuando un sofista, quizás mediocre como Onomarco de

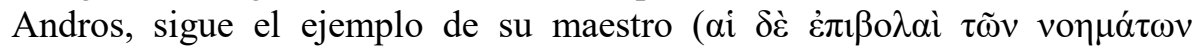

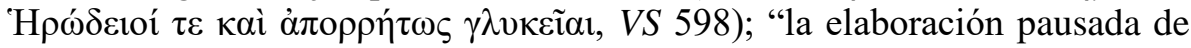

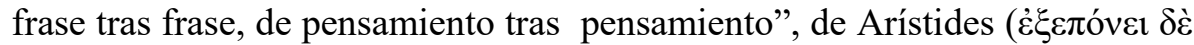

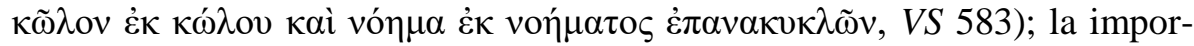
tancia del redondeo de un "pensamiento tras otro en periodos de extensión semejante" para asegurar la contención del ritmo, como ya hiciera Isócrates

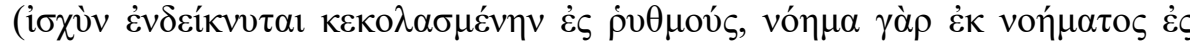

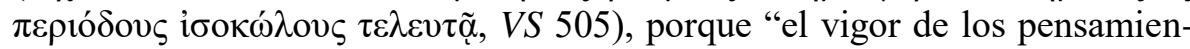
tos", como sirve de ejemplo el modus dicendi de Antípatro, puede sucumbír al ritmo de la exposición (

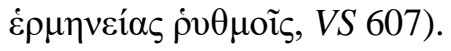

Finalmente, en esta urdimbre de vidas, Filóstrato no descuida los lazos personales, de amistad, tejidos entre maestros y discípulos no solo por un trato quizás reiterado - no en vano poı verbo que también indica "asistir a la escuela de alguien", "frecuentar a un maestro"-; un vínculo que se hace especialmente visible cuando el discípulo rinde homenaje fúnebre a su maestro, precisamente a través de la palabra que este le enseñó a cultivar, en uno de los géneros de mayor solemnidad públi-

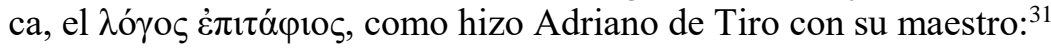

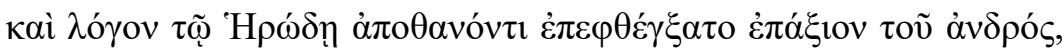

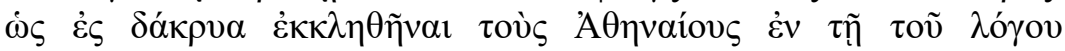

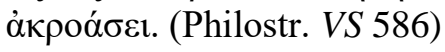

\footnotetext{
${ }^{31}$ RIFE (2009: 100-129) analiza el valor cohesionador de las prácticas funerarias entre la élite cultural que los sofistas representan.
}

Stylos. 2021; 30 (30); pp. 155-181; ISSN: 0327-8859; E-ISSN: 2683-7900 
A la muerte de Herodes pronunció en su honor un discurso digno de su talla humana, de calidad tal que hizo derramar lágrimas al pueblo ateniense que escuchaba sus palabras.

Pero igualmente Filóstrato destaca la expresión de ese vínculo de devoción por parte del maestro hacia un discípulo, como muestra Hipódromo de Tesalia: ${ }^{32}$

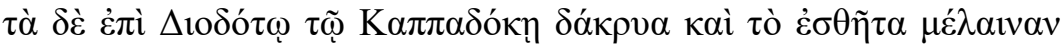

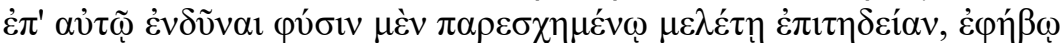

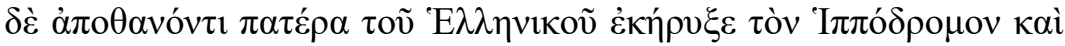

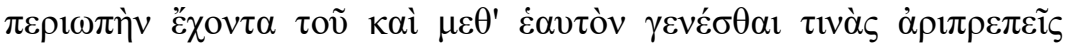

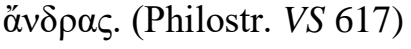

Su llanto por Diódoto de Capadocia y el luto que vistió por este joven, que mostraba excelentes dotes para la declamación y murió en la flor de la juventud, proclaman a Hipódromo padre de los alumnos de la escuela retórica y maestro que llevaba la noble mira de que existieran, después de él, hombres insignes.

En definitiva, a pesar de los muchos matices que una obra poliédrica como las Vidas de los sofistas ofrece, no cabe duda de que la conexión entre maestros y discípulos reflejada en los relatos biográficos deja al descubierto que para sus sofistas la cultura personal, aprendida del maestro, legada a los discípulos, aparece como el más preciado bien, porque, como afirma Plutarco, «la instrucción es lo único que en nosotros es inmortal y divino» ( $\pi \alpha 1 \delta \varepsilon i ́ \alpha$

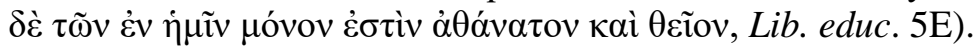

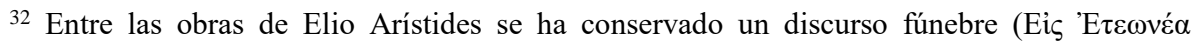
$\dot{\varepsilon} \pi \iota \hat{\delta} \delta \varepsilon 10 \varsigma$, Or. XXXI Keil) dedicado a Etoneo, en el que el sofista no solo traza la semblanza de su joven discípulo, sino que da a conocer muchos aspectos sobre la educación y el ejercicio de la retórica en el s. II; cf. VIX (2002: 4-12).
}

Stylos. 2021; 30 (30); pp. 155-181; ISSN: 0327-8859; E-ISSN: 2683-7900 


\section{REFERENCIAS BIBLIOGRÁFICAS}

Avotins, I., "The Holders of the Chairs of Rhetoric at Athens", Harvard Studies in Classical Philology, 1975, 79: 313-324.

BORG, B.E., "Glamorous intellectuals: Portraits of pepaideumenoi in the second and third centuries A D", 157-178. En: B.E. Borg (ed.), Paideia: The World of the Second Sophistic, Berlin, De Gruyter, 2004.

Bowersock, G.W., "Philosophy in the Second Sophistic", 125-131. En: G. Clark y T. Rajak (eds.), Philosophy and Power in the Graeco-Roman World: Essays in Honour of Miriam Griffin, Oxford, Oxford University Press, 2002.

CAmpanile, M.D., "Vivere e morire da sofista: Adriano di Tiro", Studi Ellenistici , 2003, 15: 245-273.

CAMPANILE, M.D. "Il sofista allo specchio : Filostrato nelle Vitae Sophistarum", Studi ellenistici 2005, 16: 275-288.

ConNOLly, J. "The New World Order: Greek Rhetoric in Rome", 139-165. En: I. Worthington (ed.), A Companion to Greek Rhetoric, Oxford, Blackwell, 2007.

CôTÉ, D. (2005), "La figure d'Eschine dans les Vies des sophistes de Philostrate", Cahiers des études anciennes , 2005, 42: 389-420.

Côté, D., "Les deux sophistiques de Philostrate", Rhetorica: A Journal of the History of Rhetoric 2006, 24(1): 1-35.

CôTÉ, D., "Sophistique et pouvoir chez Philostrate", Cahiers des études anciennes, 2010, 47: 475-502.

CRIBIORE, R., Gymnastics of the Mind: Greek Education in Hellenistic and Roman Egypt, Princeton/Oxford, Princeton University Press, 2001.

EshlemAN, K., "Defining the circle of Sophists: Philostratus and the construction of the Second Sophistic", Classical Philology, 2008, 103(4): 395-413.

GóMEZ, P., "Sofistas, según Luciano", 277-284. En: J.Mª NIETO IBÁÑEZ (ed.), Lógos hellenikós. Homenaje al Profesor Gaspar Morocho Gayo, vol. I, León, Universidad de León, 2003.

GONZÀLEZ JULIÀ, LL., "El precio de las palabras: salarios y contratos de sofistas y maestros en los documentos papiráceos", Cuadernos de Filo-

Stylos. 2021; 30 (30); pp. 155-181; ISSN: 0327-8859; E-ISSN: 2683-7900 
logía Clásica: Estudios griegos e indoeuropeos, 2010, 20: 159-178.

HENDERSON, I. "The Second Sophistic and Non-Elite Speakers", 23-35. En: Th. Schmidt y P. Fleury (eds.), Perceptions of the Second Sophistic and Its Times - Regards sur la Seconde Sophistique et son époque, Toronto, University of Toronto Press, 2011.

LAUWERS, J., "Systems of Sophistry and Philosophy: The Case of the Second Sophistic", Harvard Studies in Classical Philology, 2013, 107: 331-363.

MESTRE, F., “Nada es seguro para el hombre', dijo el sofista”, 273-281. En: Actas del VIII Congreso Español de Estudios Clásicos, Vol. 2, Madrid, Ediciones Clásicas, 1994.

Mestre, F. - Gómez, P., "Les Sophistes de Philostrate", 333-369. En: N. Loraux y C. Miralles (eds.), Figures de l'intellectuel en Grèce ancienne, de Paris, Belin, 1998.

PERNOT, L., "L'art du sophiste à l'époque romaine : entre savoir et pouvoir", 126-142. En: C. Lévy, B. Besnier y A. Gigandet (eds.), Ars et Ratio. Sciences, art et métiers dans la philosophie hellénistique et romaine, Bruxelles, Latomus, 2003.

RAIMONDI, M., "L'attidografia dall'erudizione tardoellenistica agli storici ateniesi Dexippo e Praxagora", 255-343. En: C. Bearzot y F. Landucci (eds.), Storie di Atene, storia dei Greci. Studi e ricerche di attidografia, Milano, Vita e Pensiero, 2010.

RIFE, J.L., "The deaths of the sophists: Philostratean biography and elite funerary practices", 100-129. En: E.L. Bowie y J. Elsner (eds.), Philostratus, Cambridge, Cambridge University Press, 2009.

STRAZDINS, E., "The King of Athens: Philostratus' Portrait of Herodes Atticus", Classical Philology, 2019, 114(2): 238-264.

VIX, J.-L., "Étéonée, vie et mort d'un étudiant de rhétorique au IIe siècle après J.-C. “, L'Information Littéraire, 2002, 1: 4-12.

WATTS, E.J., City and School in Late Antique Athens and Alexandria, Berkeley-Los Angeles-London, University of California Press, 2006.

WEBB, R., "Schools and Paideia", 139-153. En: D. S. Richter y W. A. Johnson, (eds.), The Oxford Handbook of the Second Sophistic, Oxford/New York, Oxford University Press, 2017.

Stylos. 2021; 30 (30); pp. 155-181; ISSN: 0327-8859; E-ISSN: 2683-7900 